\title{
A semi-systematic review on hypertension and dyslipidemia care in Egypt—highlighting evidence gaps and recommendations for better patient outcomes
}

\author{
Ashraf Reda ${ }^{1 *}$ D, Hany Ragy ${ }^{2}$, Kanwal Saeed ${ }^{3}$ and Mohammed Ashraf Alhussaini ${ }^{4}$
}

\begin{abstract}
Background: Both hypertension and dyslipidemia are considered as major modifiable risk factors of cardiovascular diseases (CVDs), and their prevalence in Egypt has increased in recent years. Evidence-based systematic evaluation of data on hypertension and dyslipidemia is critical for effective patient-centric management to reduce the overall risk of CVDs in Egypt. This semi-systematic review aimed to quantify and identify data gaps in the prevalence and distribution of patient journey touchpoints including awareness, screening, diagnosis, treatment, adherence, and control of hypertension and dyslipidemia to provide the basis for research prioritization, practice guidance, and health care reforms in Egypt.

Main body: Structured search was conducted on MEDLINE and Embase to identify articles published in English between January 2010 and December 2019 that reported key patient journey touchpoints in hypertension and dyslipidemia management. Unstructured search was conducted on public or government websites with no date restriction. Data from all sources were extracted and presented descriptively. In total, 22 studies published between 1995 and 2020 on hypertension and dyslipidemia were included in the final analyses. The prevalence of hypertension in Egypt ranged from 12.1 to 59\%. Studies reported awareness (37.5\% and 43.9\%), diagnosis (42\% and $64.7 \%$ ), treatment (24\% and $54.1 \%$ ), and adherence to antihypertensive medication (51.9\%) to be low. Furthermore, the percentage of patients who had their blood pressure controlled ranged from 8 to $53.2 \%$. The prevalence of dyslipidemia varied in the general population (range 19.2-36.8\%) but was higher in patients with acute coronary syndrome (ACS) (50.9\% and 52.5\%) and coronary artery disease (58.7\%). A national report indicated that $8.6 \%$ of the general population was screened for dyslipidemia; however, no data was available on the diagnosis and treatment rates. Among ACS patients, 73.9\% were treated for dyslipidemia. Data indicated low levels of medication adherence (59\%) among dyslipidemia patients, with overall low control rates ranging from 5.1 to 34.4\% depending on CVD risk in populations including ACS patients.
\end{abstract}

\footnotetext{
* Correspondence: ashrafreda5555@gmail.com

1Department of Cardiology, Menoufia University, Shebin El Kom, Egypt

Full list of author information is available at the end of the article
}

\section{Springer Open}

(c) The Author(s). 2021 Open Access This article is licensed under a Creative Commons Attribution 4.0 International License, which permits use, sharing, adaptation, distribution and reproduction in any medium or format, as long as you give appropriate credit to the original author(s) and the source, provide a link to the Creative Commons licence, and indicate if changes were made. The images or other third party material in this article are included in the article's Creative Commons licence, unless indicated otherwise in a credit line to the material. If material is not included in the article's Creative Commons licence and your intended use is not permitted by statutory regulation or exceeds the permitted use, you will need to obtain permission directly from the copyright holder. To view a copy of this licence, visit http://creativecommons.org/licenses/by/4.0/. 
Conclusion: Data on patient journey touchpoints of hypertension and dyslipidemia are limited in Egypt, indicating the need for more systematic and high-quality evidence-based studies covering different aspects of patient-centric management for better management of CVD and its risk factors.

Keywords: Cardiovascular disease, Dyslipidemia, Egypt, Hypertension, Patient-centric, Prevalence, Touchpoints

\section{Background}

Noncommunicable diseases (NCDs) were responsible for 42 million deaths worldwide in 2019 , with a majority of these deaths (18.6 million) attributed to cardiovascular diseases (CVDs) [1]. There is an increasing focus on reducing mortality due to NCDs by 2030 , as proposed by the World Health Organization (WHO) under the Sustainable Development Goals [2]. Despite these efforts, there was an increase in CVD mortality rate in the lowand middle-income countries (LMICs) between 2000 and 2012 [3], which contributed to $80 \%$ of global CVD deaths [4].

Egypt, classified as an LMIC by the World Bank, reported an annual mortality rate of $40 \%$ due to CVDs. Being the most populous country in the Middle East and North African region, Egypt accounted for 15\% of the CVD mortality for the entire region [5-7]. The high CVD mortality in Egypt was attributed to increasing urbanization in the country, accompanied by widening gaps in the socio-economic statuses, increasing westernization of lifestyles, and rising imbalance between improved health services and accessibility to the population [3, 8-12]. These changes explained the rise in the prevalence and possible complications in the management of modifiable and preventable CVD risk factors such as hypertension and dyslipidemia [13]. The most recent global estimates suggested that hypertension affected 1.13 billion people worldwide [14]. According to the WHO global estimates, the prevalence of dyslipidemia among adults is also quite high at 39\% [15]. In Egypt, a few population-based studies have estimated the prevalence of CVD risk factors; the most recent national survey reported the prevalence of hypertension and dyslipidemia at $29.5 \%$ and $19.2 \%$, respectively [16].

The management of hypertension in Egypt was affected by multiple factors such as an inconsistent approach adopted by the physicians to measure blood pressure, inadequate treatment, lower number of patients achieving target blood pressure, lower awareness of hypertension among patients, limited use of risk assessment tools to identify high-risk patients, patient noncompliance to treatment, lack of preventive centers, and absence of national registries for CVD risk factors [5, 17-20]. On the other hand, despite higher awareness regarding dyslipidemia, patients were severely undertreated and were unable to reach the target lipid levels while on treatment in Egypt $[21,22]$. In addition, there was a lack of appropriate programs for the prevention and timely detection of these two CVD risk factors [23]. Owing to the lack of epidemiologic studies on prevalence or clinical trial data regarding the management of hypertension or dyslipidemia in Egypt, most of the treatment practices were adapted from the evidence-based guidelines of western countries, with modifications based on the cultural, economic, and social lifestyle of the region [24]. Current epidemiology, practices, and overall status of hypertension and dyslipidemia in the local population should advocate incremental reforms in the health care sector, emphasizing on promoting patient awareness, incorporating screening programs, improved treatment, and control of these diseases in Egypt [2427]. The evaluation of the influence of health care services on patients' engagement along the common determinants of patient journey touchpoints including awareness, screening, diagnosis, treatment, adherence, and control was recognized as the opportunity to address the unmet needs [28]. However, there is a paucity of evidence-based, high-quality data on these patientcentric outcome measures that would support health care professionals in managing CVDs at the national level. The first step to solve these hindrances is to collect and summarize the existing evidence on the broad research question, which can be done effectively using evidence mapping [29-31].

This semi-systematic review aimed at summarizing the scientific evidence on the prevalence and patient journey stages of hypertension and dyslipidemia in the Egyptian population that would boost policy and practice improvements in the country.

\section{Main text}

\subsection{Methods}

\subsubsection{Study design}

We conducted a comprehensive semi-systematic data review using structured and unstructured literature searches for retrieval of data on prevalence and various phases of patient-centric management (awareness, screening, diagnosis, treatment, adherence, and control) of hypertension and dyslipidemia in the Egyptian population. The current review adopted the methodological approach described earlier in an associated protocol [32], with minor modifications to address variability in the data or lack of availability of data. 


\subsubsection{Search strategy}

We followed a multi-component search strategy. First, a structured search was conducted on the electronic databases MEDLINE and Embase using relevant search strings including Medical Subject Heading (MeSH) terms and their synonyms to identify different phases of patient journey touchpoints for hypertension and dyslipidemia in Egypt. The full search strategy is presented in Supplementary Table 1.

An additional unstructured search was conducted in the Incidence and Prevalence Database (IPD), the WHO and Ministry of Health websites, and Web search engines (the search included a combination of the key $\mathrm{MeSH}$ terms from the systematic literature search, with no restrictions on date limits identified in the additional searches).

\subsubsection{Inclusion and exclusion criteria}

The structured search was restricted to systematic reviews and/or meta-analyses, narrative reviews, randomized controlled studies, and observational studies published in the English language from January 1, 2010, to December 31, 2019. Studies with quantitative data on prevalence or at least one component of patient management (awareness, screening, diagnosis, treatment, adherence, and control) involving human adult populations aged $\geq 18$ years were included. Studies involving patient population with hypertension or dyslipidemia, where hypertension was defined as average systolic blood pressure $\geq 140 \mathrm{mmHg}$ and/or average diastolic blood pressure $\geq 90 \mathrm{mmHg}$ [33] and dyslipidemia was defined as average total cholesterol levels $\geq 5.0 \mathrm{mmol} / \mathrm{L}$ or $\geq 190.0$ $\mathrm{mg} / \mathrm{dL}$ [34], were included.

Studies were excluded if they did not focus on hypertension or dyslipidemia or representative of the national population of Egypt. Case studies, letters to the editor, editorials, and studies on special population (pregnant patients, patients with other comorbidities) were also excluded.

\subsubsection{Study selection}

Primary screening and data retrieval were performed by the first independent reviewer on the basis of the titles and abstracts. In the second level of screening, studies were shortlisted by a second independent reviewer on the basis of the pre-defined eligibility criteria and fulltext review; any disagreements between the reviewers were resolved through mutual scientific discussions. To account for the unavailability of data on hypertension and dyslipidemia at the national level, additional studies were considered appropriate for inclusion to supplement data collected from structured and unstructured searches. Furthermore, a prominent deviation from the protocol was proposed to adopt a secondary approach, which allowed inclusion of studies conducted on relevant subpopulations (e.g., patients presenting with acute coronary syndrome (ACS)) that could be translated to the real-world setting in the context of prevention and management of these 2 risk factors. The shortlisted studies from all sources were analyzed in detail before including in the final records.

\subsubsection{Data extraction and synthesis}

Studies included in the final records were exported to Microsoft Excel after manual screening, followed by retrieval of relevant quantitative data including prevalence of hypertension and dyslipidemia, as well as different phases of patient-centric management (awareness, screening, diagnosis, treatment, adherence, and control). To ensure consistency with real-world experiences, extracted quantitative data were further reviewed and verified.

\subsection{Results \\ 2.2.1 Screening of studies for hypertension}

A total of 277 articles from the structured searches and 6 articles from the unstructured searches were retrieved on the prevalence and the distribution of patient journey stages of hypertension. Most of the studies that were excluded represented specific patient subgroups (pregnant women, patients with other comorbidities, $n=117$ ). Other studies were excluded for not focusing on hypertension $(n=106)$, not representing adult population ( $n$ $=29$ ), not reporting data on any of the phases of patient-centric management $(n=8)$, non-availability of full-text article $(n=4)$, and published in a non-English language $(n=1)$. The search results and subsequent data analysis at a later stage allowed inclusion of studies conducted in the subgroup of patients presenting with ACS and coronary artery disease (CAD). Twelve articles from the structured searches and all 6 articles from the unstructured searches were selected for detailed review. Further, 3 additional studies were considered as supplementation to the shortlisted records. Finally, 4 articles from the structured searches [6, 25, 26, 35], 5 studies from the unstructured searches [8, 16, 20, 36, 37], and 2 supplementary studies were included in the final analysis $[38,39]$. Ten studies were excluded because of the following reasons: small sample size $(n=1)$, meta-analysis $(n=1)$, duplicate records $(n=3)$, variable definition of hypertension $(n=1)$, availability of similar national data $(n=1)$, questionnaire-based studies without proper definition of hypertension $(n=1)$, anecdotal data $(n=1)$, or studies focused on single-pill combination therapy $(n=1)$. The literature search and study selection process is summarized in Fig. 1. 


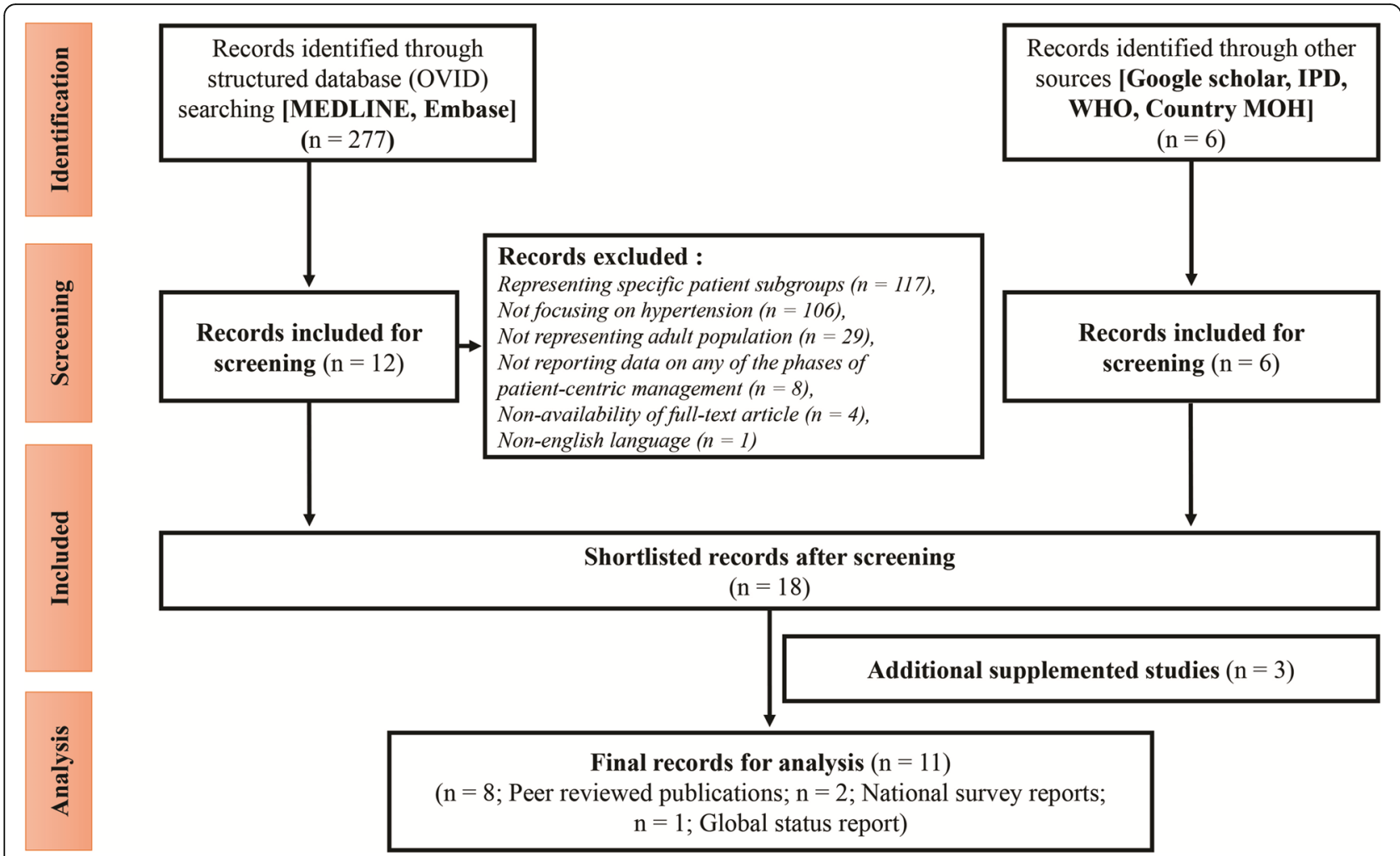

Fig. 1 Flowchart of literature search results on hypertension.

IPD, Incidence and Prevalence Databases; MOH, Ministry of Health; WHO, World Health Organization

\subsubsection{Description of included studies: hypertension}

Three studies including a WHO Global Status Report on NCDs, a nationwide cross-sectional community-based survey, and an Egyptian National Hypertension Project reported prevalence of hypertension ranging from 26 to $29.5 \%$ among Egyptian adults [16, 36, 37]. The prevalence of high blood pressure in men and women among the Egypt Health Issues Survey (EHIS) respondents at the time of the survey were $16.7 \%$ and $17.2 \%$, respectively [38]. A systematic analysis of a national health examination survey conducted by Ikeda et al. [25] reported hypertension prevalence at $12.1 \%$ among individuals aged between 35 and 49 years. In a multicenter, cross-sectional study in Egyptian patients with ACS, the prevalence of hypertension was estimated at 59\% [6]. A comparative study between elderly and younger patients with ACS revealed 49.1\% incidence of hypertension among the younger population ( $<60$ years) [35]. In a retrospective study, hypertension was reported in $56.7 \%$ of patients with CAD [26].

The data obtained from the most recent EHIS [39] revealed that $43.9 \%$ of the Egyptian adult population was aware of their hypertensive condition, whereas only $22.7 \%$ of population could achieve blood pressure control. Similarly, awareness about hypertension in the Egyptian National Hypertension Project was estimated at
$37.5 \%$ [37]. The EHIS showed that $42 \%$ of the surveyed population was diagnosed with hypertension [38]. In a systematic review of hypertension in 20 countries, $64.7 \%$ of the surveyed population was diagnosed with hypertension, whereas $54.1 \%$ received treatment and $39.5 \%$ reported control of blood pressure in Egypt [25]. On the basis of the data from Egyptian National Hypertension Project, $24 \%$ of hypertensive patients received treatment, whereas only $8 \%$ of the patients reported control of blood pressure [37]. A multistage random sampling technique at health insurance clinics in Egypt reported controlled blood pressure in $53.2 \%$ of the hypertensive patients and adequate compliance to treatment in 51.9\% of the patients [20]. A nationwide Specialized Hypertension Clinics (SHCs) screening and treatment initiative reported that only $27.1 \%$ of the hypertensive patients had controlled blood pressure [8]. No study provided data on screening of hypertension in the Egyptian population. The details of the studies included in the final analysis are summarized in Table 1.

\subsubsection{Screening of studies for dyslipidemia}

A total of 251 articles from the structured searches and 4 articles from the unstructured searches were retrieved on prevalence and patient-centric management of dyslipidemia for the Egyptian population. Studies representing 


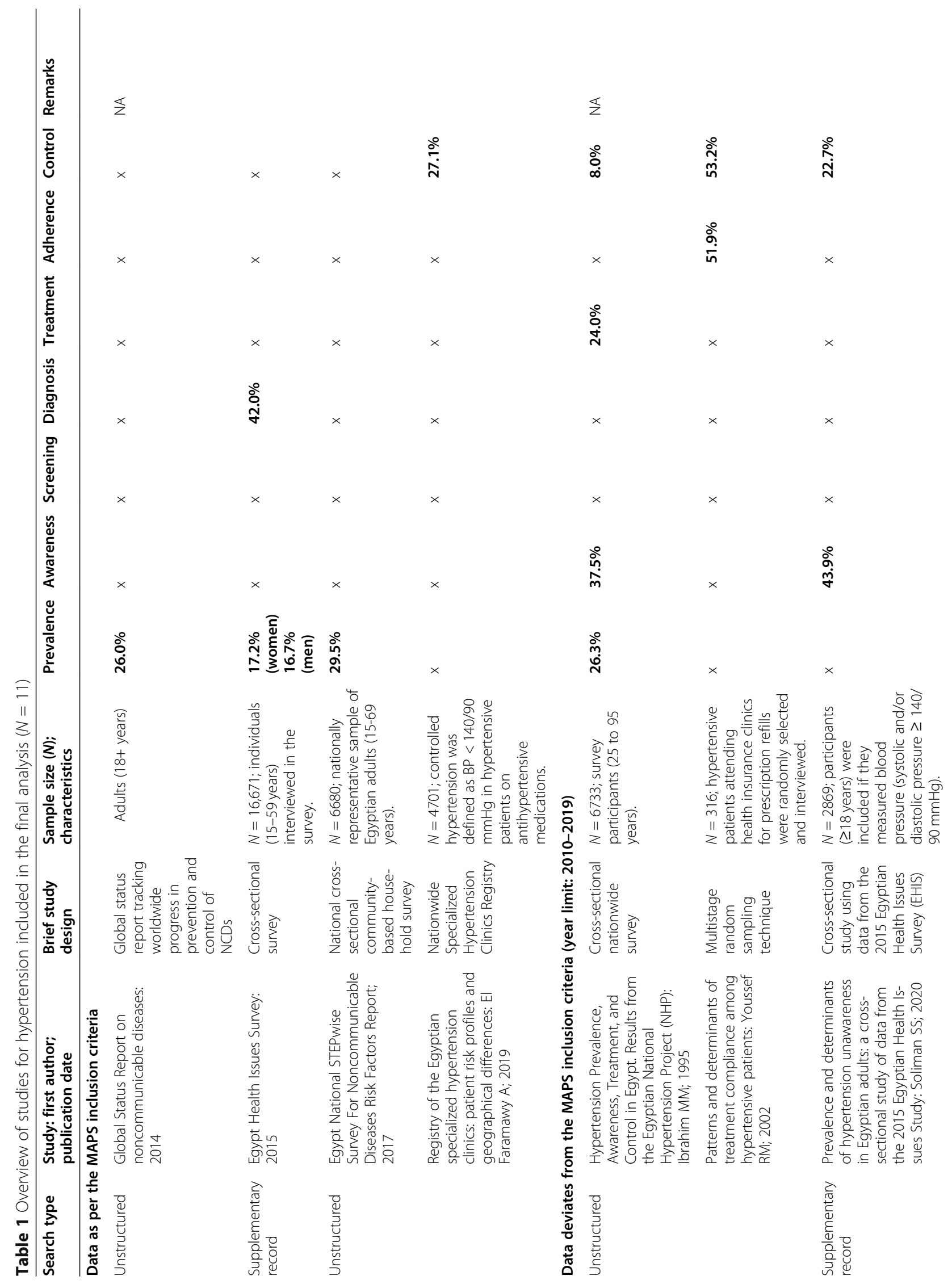




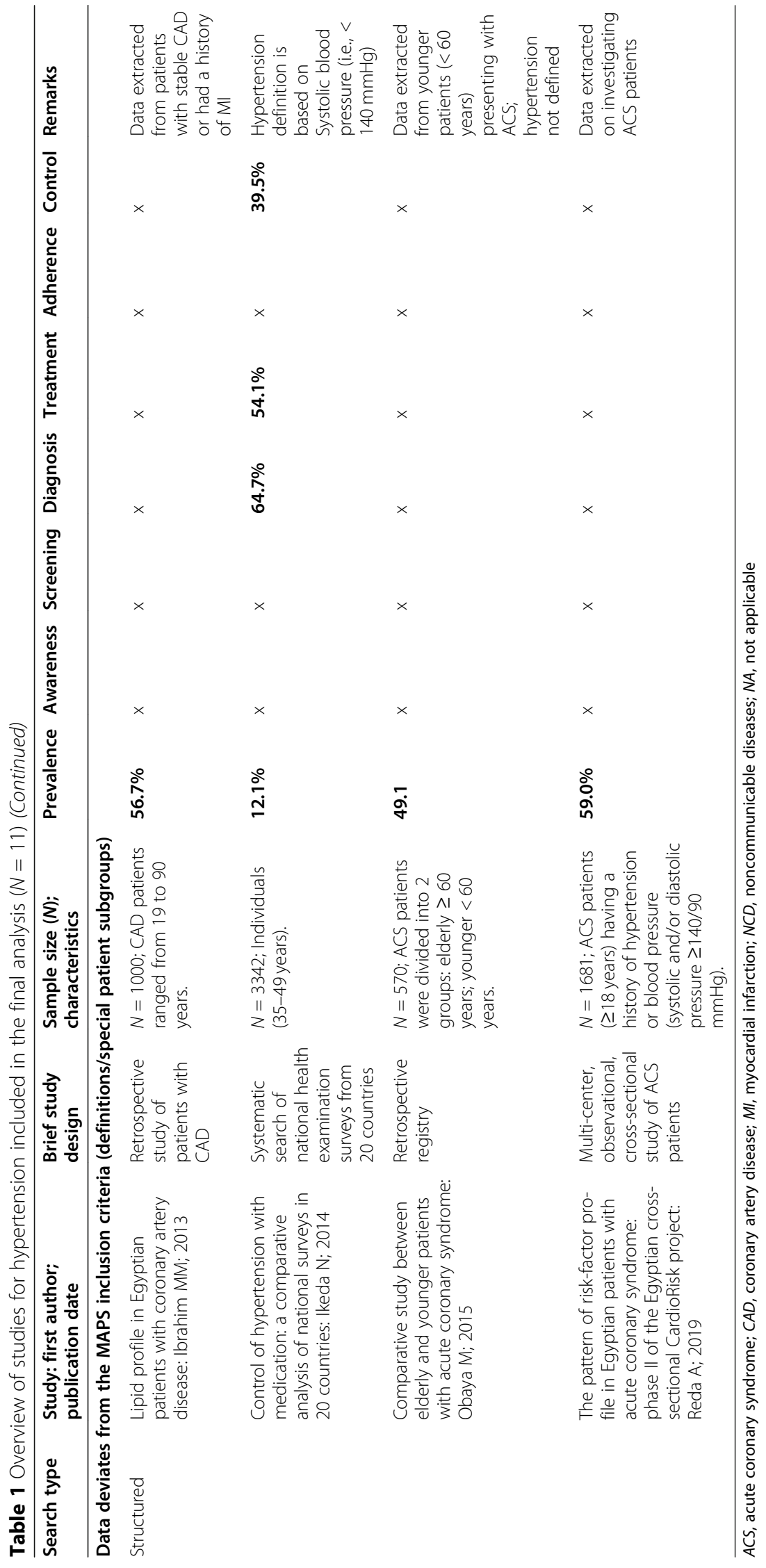


specific patient subgroups (pregnant women, patients with other comorbidities, $n=114$ ), not reporting data on prevalence or any of the phases of patient-centric management $(n=57)$, not focusing on dyslipidemia $(n=$ $39)$, not representing adult population $(n=16)$, nonavailability of full-text article $(n=8)$, lack of nationallyrepresentative population $(n=3)$, case studies, letters to the editor, editorials $(n=2)$, duplicate records $(n=2)$, and data not from the representative country $(n=2)$ were excluded. The findings of the initial data review indicated lack of data on dyslipidemia in the general population and thus necessitated inclusion of patient subgroups diagnosed with ACS or CAD at a later stage. Eight articles from the structured searches, and all 4 articles from the unstructured searches were considered eligible for review. An additional survey-based study on NCDs risk factors in Egypt was supplemented to the shortlisted records for assessment. Finally, 8 articles from the structured searches $[6,8,21-23,26,35,40], 2$ nationwide survey reports from the unstructured search $[41,42]$, and 1 additional study was included in the final analysis [16]. Two of the selected studies were not considered for final analysis because of the availability of the similar data in the STEPS Survey reports. The literature search and study selection process are summarized in Fig. 2.

\subsubsection{Description of included studies: dyslipidemia}

On the basis of the nationwide survey data, the prevalence of hypercholesterolemia was $19.4 \%, 36.8 \%$, and $19.2 \%$ in the Egyptian population during 2006, 2012, and 2017, respectively [16, 41, 42]. However, cholesterol screening was poor, as reported in one nationwide survey $(8.6 \%)$ [16]. A nationwide, cross-sectional CardioRisk study conducted in patients with ACS reported increased low-density lipoprotein cholesterol (LDL-C) levels in $52.5 \%$ of the patients [6]. Similarly, another retrospective study reported a prevalence of dyslipidemia in $50.9 \%$ of younger patients ( $<60$ years) diagnosed with ACS [35]. The high prevalence of dyslipidemia (58.7\%) based on total cholesterol levels was also identified in Egyptian patients with CAD [26]. However, in a group of hypertensive Egyptians attending SHCs, the prevalence of dyslipidemia was only $8.9 \%$ [8].

The results from both the Centralized Pan-Middle East Survey on the under-treatment of hypercholesterolemia (CEPHEUS) studies in Egypt indicated that most patients were aware of their target cholesterol levels (76\%) or bad cholesterol (75\%) [23, 40]. Although compliance to treatment of dyslipidemia in the CEPHEUS II study was reported at 59\% [40], target LDL-C levels were achieved in only $32.5 \%$ and $34.4 \%$ of the patients as reported in the CEPHEUS I and CEPHEUS II results,

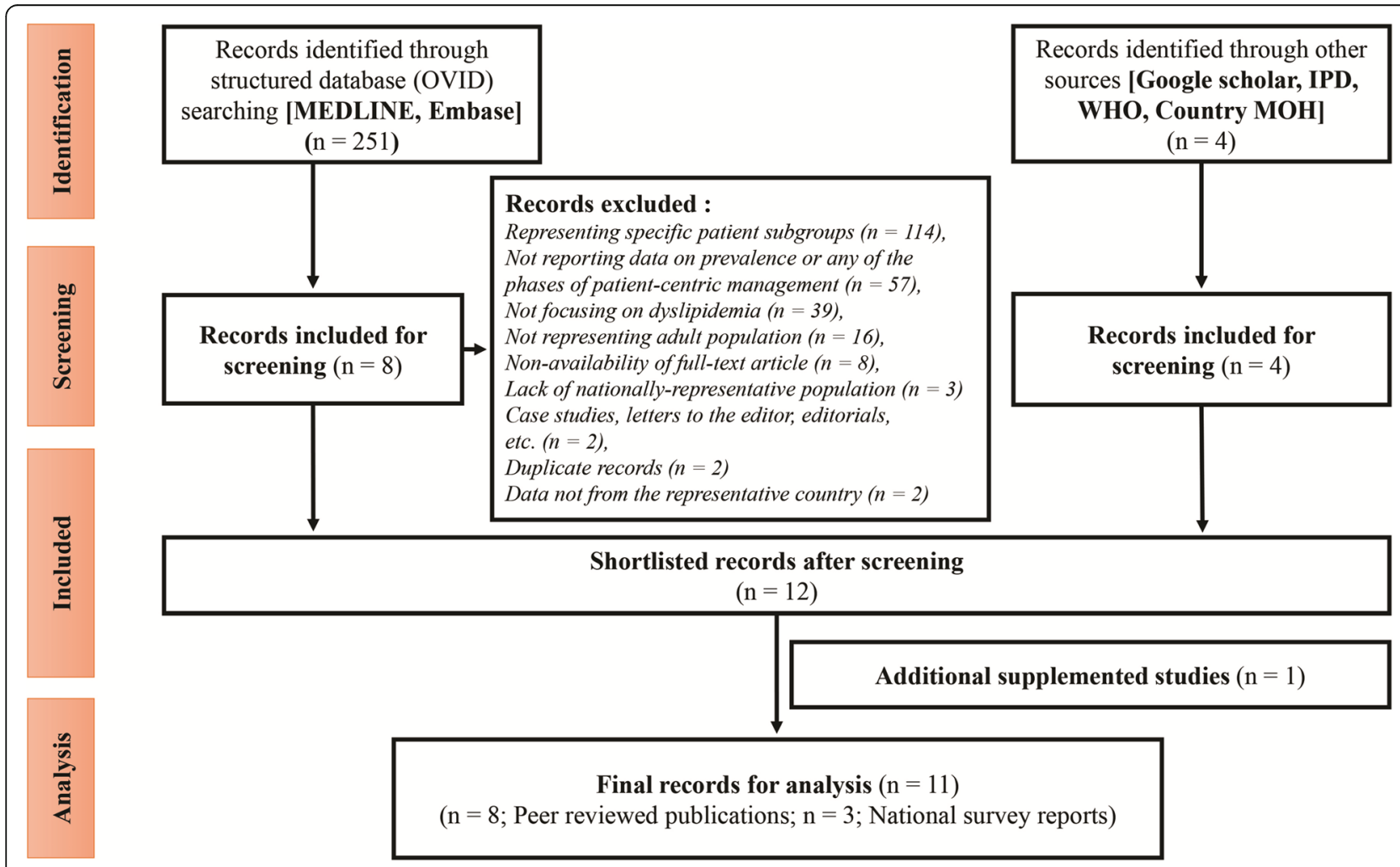

Fig. 2 Flowchart of literature search results on dyslipidemia.

IPD, Incidence and Prevalence Databases; $\mathrm{MOH}$, Ministry of Health; WHO, World Health Organization 
respectively [23, 40]. According to the DYSlipidemia International Study (DYSIS)-Egypt, one-third of the patients who received chronic statin treatment had control in LDL-C levels [21]. In the DYSIS II study, $73.9 \%$ of patients with ACS received treatment for dyslipidemia, whereas the proportion of patients who achieved target LDL-C levels varied within different risk categories, with $5.1 \%$ at very high risk, $27.3 \%$ at high risk, $32.3 \%$ at moderate risk, and $14.3 \%$ at low risk [22]. No study provided data on diagnosis of dyslipidemia in the Egyptian population. The details of the studies included in the final analysis are summarized in Table 2.

\subsection{Discussion}

This semi-systematic review, for the first time, presented the evidence available and identified inconsistencies in reporting the data on prevalence and patient journey stages (awareness, screening, diagnosis, treatment, adherence, and control) of hypertension and dyslipidemia in Egypt. Despite performing a comprehensive literature review, only 22 studies (11 studies each for hypertension and dyslipidemia) were found to be relevant for the final analysis. Data were available on prevalence and all phases of patient-centric management of hypertension, except screening rates, whereas data were available on the prevalence and all phases of patient-centric management of dyslipidemia, except diagnosis rates.

\subsubsection{Comparison with other studies on hypertension}

The studies included in this review demonstrated a wide variability in the prevalence of hypertension, which could be explained by differences in population characteristics, subgroup analysis, and study methodologies. The prevalence estimates were lower in the younger general population aged between 35 and 49 years (12\%) [25] and surveyed population aged $<60$ years (17\%) [38], whereas the estimates were higher ranging from 49 to $59 \%$ in subgroup studies of patients with ACS and CAD, indicating hypertensive patients were more susceptible to develop CVDs $[6,26,35]$. However, the prevalence of hypertension in the general Egyptian population did not vary and ranges between 26 and 29.5\% [16, 36, 37], which were comparable to the prevalence reported in the LMICs (31\%) [43] and the USA (29\%) [44].

Our study demonstrated that the levels of awareness of hypertension (38\% and 44\%) [37, 39] in the Egyptian population were comparable with those in LMICs (38\%), but markedly lower when compared with that in the high-income countries (HICs) (67\%) [45]. Consequently, the percentages of diagnosed hypertensive individuals in Egypt were $42 \%$ and $65 \%$ in 2 studies [25, 38], which were comparable to the range reported for various LMICs (46-75\%), but substantially lower compared to the USA (85\%) [25]. Further, we observed a wide variability in the proportion of patients treated for hypertension (24\% and 54\%) [25, 37], which was not consistent with the treatment rates reported for LMICs (29\%) and HICs (56\%) [45]. In our review, patient compliance to treatment for hypertension was reported at $52 \%$, which was higher than the patient compliance reported in a recent study (41\%) [46]. Lower compliance to anti-hypertensive medication could be attributed to increased cost, side effects, monotherapy, and lack of efficacy [20]. Similarly, there is a wide variability in the blood pressure control rates as reported in our review ranging from as the lowest estimate of $8 \%$ to the highest estimate of $53 \%[8,20,25,37,39]$, whereas the control rates were reported at $27 \%$ in LMIC and $51 \%$ in $\mathrm{HICs}$ [45]. This trend in the rates of awareness, treatment, adherence, and control of hypertension in the Egyptian population that mimicked the trends in LMICs might be related to lack of compliance with evidence-based treatment, unavailability of simplified recommendations, and higher diagnostic thresholds limiting early detection and treatment initiation $[43,47,48]$.

\subsubsection{Comparison with other studies on dyslipidemia}

According to the STEPS reports, the prevalence of dyslipidemia in the general population of Egypt fluctuated from $19.4 \%$ in 2006 to $36.8 \%$ in 2012 and reduced to $19.2 \%$ in 2017 [16, 41, 42]. Although reasons for wide variability in prevalence could not be identified, such evidence will be useful for future endeavors in planning large-scale studies in implementing treatment interventions or health care policies. Among Egyptian patients with ACS and CAD, the prevalence of dyslipidemia was consistently higher within the range between 51 and $59 \%$, which reinforced the latter's status as a major risk factor in CVDs [6]. There was a correlation between the 2 risk factors when a study in hypertensive patients reported prevalence of dyslipidemia in $9 \%$ of the patients [8]. It is imperative to identify such high-risk patients with the presence of multiple risk factors so that they can be targeted for treatment to reduce CVDs. The prevalence of dyslipidemia reported in the general Egyptian population was much lower than that projected by the WHO (39\%). Further, the prevalence of high cholesterol in Egypt was comparatively lower than that reported in the USA (55\%) and UK (66\%) [15]. Data from both the CEPHEUS studies indicated a higher level of awareness in patients about their cholesterol levels $(\geq 75 \%)$, with a moderate level of adherence to the therapeutic regimen $(59 \%)[23,40]$. However, there was a possibility of recall bias, which is commonly seen in survey studies. Similarly, the proportion of patients treated (74\%) was relatively higher when analyzed in a small cohort of patients suffering from ACS [22], which may not be representative of the overall Egyptian population. 


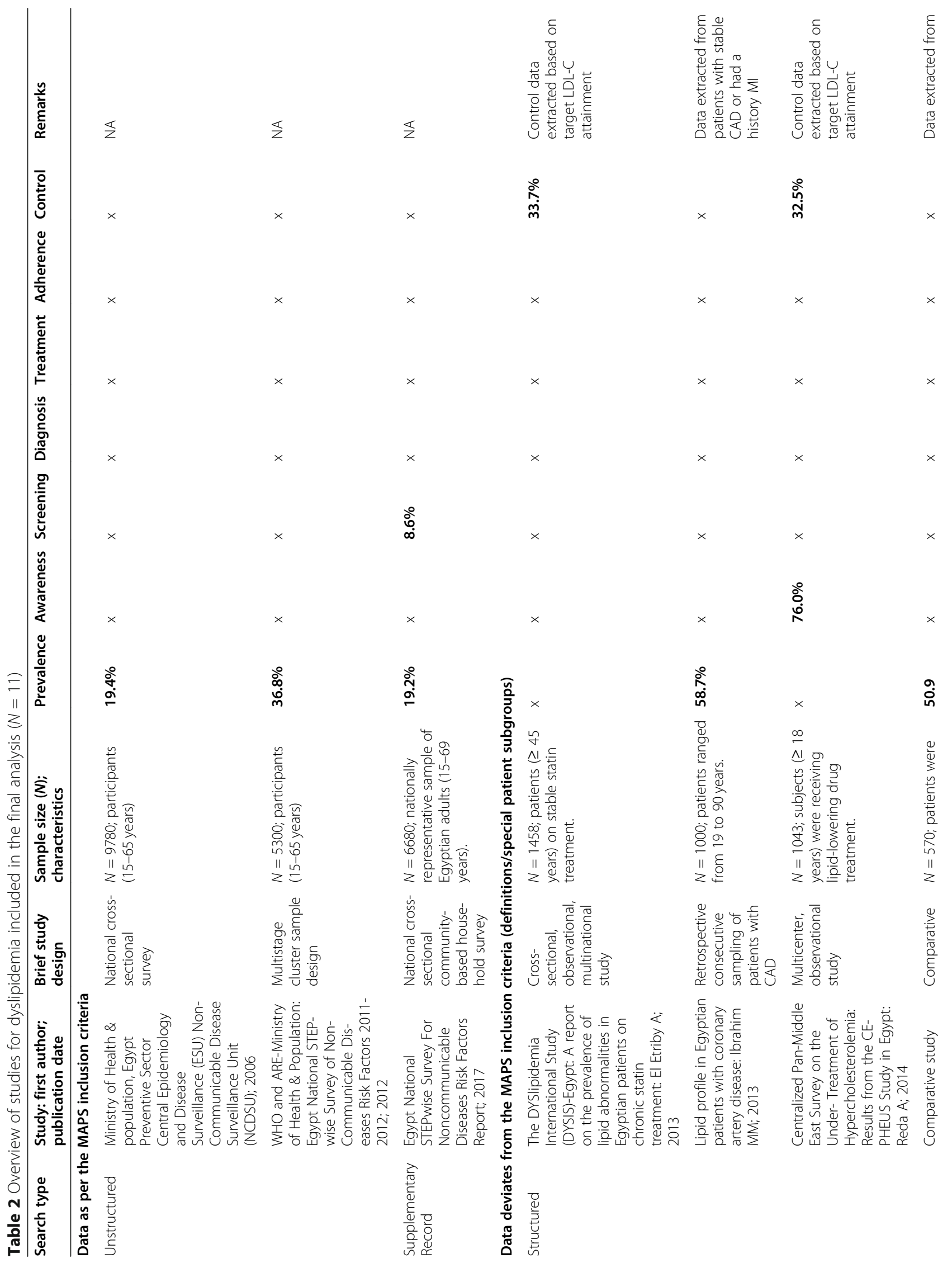




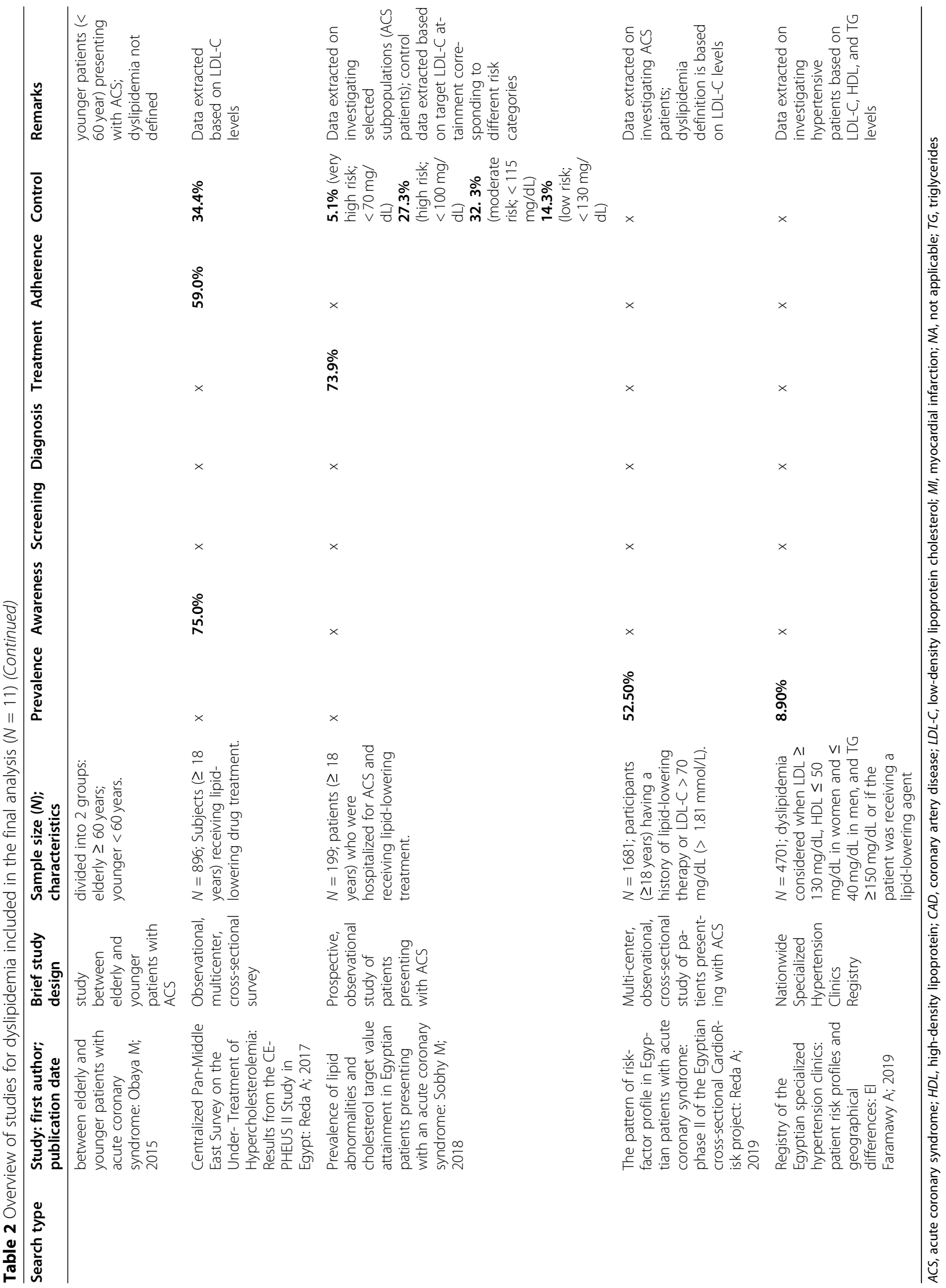


Although the treatment rates of dyslipidemia were higher, the overall control rates were lower in the general population as well as in patients with ACS, ranging from 20 to $34 \%$ [21-23, 40]. These lower control rates could be attributed to a lack of implementation of evidence-based guidelines, clinical inertia, and patients' non-compliance to the prescribed treatment [49]. Similarly, less affordability to costly medications and "ceiling effect" on LDL-C lowering by statin therapy could be the reason for poor control rates in the lipid levels $[50,51]$.

\subsubsection{Implications for practice and patient-centric recommendations}

Suboptimal control of hypertension reflected lack of education and limited medical access in Egypt, indicating the need for collaborative efforts from health authorities, medical community, and pharma companies to promote patient education and national level campaigns $[19,52]$. Further, there is a need for specialized hypertension clinics in Egypt to improve quality and accessibility to health care services for the patients [11]. Egypt is now steadily progressing with its recent initiative to develop a nationwide screening program "100 Million Healthy Lives" accompanied by awareness and treatment campaigns for NCDs such as hypertension and diabetes" [53]. Thus, it would be crucial to publish these reliable and meaningful findings allowing the use of the credible information to aid policymakers to identify the target population for their interventions and policies. Moreover, extending the campaign to dyslipidemia would impart a comprehensive coverage of the CVD landscape in Egypt. In addition to these measures, there is a need to conduct large epidemiological studies encompassing cultural and ethnic contexts and studies comparing evidence-based treatment and current treatment approaches in Egypt to improve the rates of awareness, treatment, and control of dyslipidemia [54, 55]. Similarly, awareness promotion, early identification, timely treatment, and cost-effective management of hypertension and dyslipidemia could be achieved by an integrated approach between affordable primary health care (PHC) services and family- or community-level focus [56-60], considering the medical resources constraint in Egypt. Although there were significant advances in the emergency management of CVDs, primary preventive care was offered by the general practitioners (GPs), whereas specialists focused on secondary preventive measures for CVDs. Owing to a lack of formal education on cardiac primary prevention, there is a need for restructuring curriculum in cardiology training with more focus on primary preventive measures [5]. Moreover, physician's lack of familiarity with diagnostic guidelines and practice recommendations indicated that there is a need to facilitate workshops, seminars, and availability of international manuals for PHCs [61]. Although the WHO has recognized Egypt's commitment in scaling up PHC facilities [62], the imbalance in care services across different regions and socioeconomic groups necessitated the adoption of comprehensive strategies leading to effective national health care reforms [63]. To achieve these reforms, the overall burden of hypertension and dyslipidemia in the Egyptian population should be estimated using a risk assessment approach. In the absence of recommendations for opportunistic screening for CVD risk assessment in the general population, the European guidelines emphasized the importance of systematic screening for CVD risk assessment in individuals who are at high risk due to positive family history for CVD risk factors [64]. Such an approach in addition to the periodic data collection to estimate the precise prevalence of risk factors and integration of populationbased surveillance programs into the national health information systems targeted toward detection, treatment, and control of CVDs could be rigorously followed as proposed in the WHO's Global Action Plan [65]. For decades, Egypt's health care sector has struggled to address the public health crisis owing to underinvestment in public hospitals, unreliable private health care, inadequate health insurance, and issues related to equity by race/ethnicity, gender, and other socioeconomic status measured by education, income, or occupation $[66,67]$. However, recently the Egyptian government has prioritized health care services for all citizens ensuring mandatory coverage eliminating existing disparities through "The Universal Health Coverage Project" [68].

In Egypt, barriers were identified toward execution of smoking prevention measures such as lack of enforcement of smoke-free laws and lack of penalties for violators [69]. National health policies and community programs targeting the concurrent risk factors such as smoking cessation, improvement in lifestyle, and innovations within the context of patient-centric care, increasing health communications, and enabling treatment adherence monitoring could be meaningful measures for hypertension and cholesterol management [70]. The implementation of an electronic monitoring system and the use of eHealth communication were found to be complicated and seemed to be underused [71]. Despite the designing of several eHealth applications, successful implementation remained a challenge in Egypt due to lack of patient acceptance, financial constraints, and limited infrastructure, especially in the rural areas [72]. However, Egypt's approach to digitize health services has witnessed an accelerated transformation with the emerging use of artificial intelligence to diagnose diseases and provide treatment solutions via telehealth and telemedicine, enabling better handling of medical data during the 
COVID-19 pandemic [73]. This holistic approach of translating digital interventions to the most vulnerable patients with greater CVD risk factors can be adopted into the National eHealth policy as well in the future.

\subsection{Limitations}

Our review has some limitations. Data on key patient journey touchpoints were not consistently available in all articles, and thus, pooled estimates of synthesized data could not be reported. Furthermore, case studies and studies conducted on some patient subgroups (e.g., pregnant women, adolescents) were excluded, and therefore, we might have missed evidence to describe some of the observations in our review. In addition, exclusion of patients with other comorbidities especially diabetes might have underestimated the actual prevalence of hypertension because of the increased occurrence of hypertension in patients with diabetes. Additionally, this study is limited by inclusion of dyslipidemia studies based only on the levels of total cholesterol and not considering other variables such as triglycerides, low-density lipoprotein, and high-density lipoprotein. It is important to note that evidence maps can provide a brief overview of topic; however, no information on efficacy of any individual treatment intervention was provided for patients with hypertension or dyslipidemia. Furthermore, in this semisystematic review of articles, critical appraisal for the quality of findings was not assessed in the included studies.

\section{Conclusion}

This study complemented the existing literature on prevalence and provided insights on different phases of patient-centric management of hypertension and dyslipidemia in Egypt. The findings supported the need for opportunistic screening for CVD risk factors when visiting a PHC facility, which in turn could result in early diagnosis and improve treatment outcomes. The need for multi-disciplinary commitment from government, policymakers, health care professionals, and other stakeholders toward the prevention of CVD risk factors, promotion of lifestyle interventions, and overall disease management systems is crucial. Finally, this study may provide a basis for research prioritization and recommendations and guidance to practice and amend health policies for the management of hypertension and dyslipidemia in Egypt. The current study reinforces the need to generate more high-quality data at national-level on prevalence of hypertension and dyslipidemia along with patient journey touchpoints to validate the conclusion of our findings.

\section{Abbreviations}

ACS: Acute coronary syndrome; CVD: Cardiovascular disease:

CEPHEUS: Centralized Pan-Middle East Survey on the under-treatment of hypercholesterolemia; CAD: Coronary artery disease; DYSIS: DYSlipidemia International Study; EHIS: Egypt Health Issues Survey; GP: General practitioner; HICs: High-income country; IPD: Incidence and Prevalence Database; LMIC: Low- and middle-income country; LDL-C: Low-density lipoprotein cholesterol; MeSH: Medical Subject Heading; NCDs: Non-communicable diseases; PHC: Primary health care; SHC: Specialized hypertension clinic; SBP: Systolic blood pressure; WHO: World Health Organization

\section{Supplementary Information}

The online version contains supplementary material available at https://doi. org/10.1186/s42506-021-00096-9.

Additional file 1: Table S1. Search Strategy for Structured Search

\section{Acknowledgements}

The authors would like to thank Aditi Karmarkar, Pfizer Upjohn and Utsavi Samel, Viatris for supporting as independent reviewers and Tanaya Bharatan, Pfizer Upjohn, for critically reviewing the draft. Medical writing and editorial support were provided by Ramu Periyasamy and Soumya Chatterjee, Indegene Pvt. Ltd, and the study was sponsored by Upjohn - A legacy Pfizer Division.

\section{Authors' contributions}

AR was involved in the study design, acquisition, analysis, interpretation of dyslipidemia data, and critical review of the manuscript. HR was involved in the study design, acquisition, analysis and interpretation of hypertension data, and critical review of the manuscript. KS was involved in the conception, acquisition of data, and analysis of hypertension and dyslipidemia data, and review of the manuscript. MA was involved in the conception, acquisition of data, and analysis of hypertension and dyslipidemia data, and review of the manuscript. All authors have read and approved the final manuscript.

Funding

This study was sponsored by Upjohn - A legacy Pfizer Division.

Availability of data and materials

The dataset generated and analyzed during the current study is not publicly available as the dataset is proprietary, but is available from the

corresponding author on reasonable request.

\section{Declarations}

Ethics approval and consent to participate

Not applicable

Consent for publication

Not applicable

\section{Competing interests}

$\mathrm{AR}$ and HR declare that they have no competing interests. KS is employed in Pfizer Upjohn and MA is employed in Viatris.

\section{Author details}

${ }^{1}$ Department of Cardiology, Menoufia University, Shebin El Kom, Egypt.

${ }^{2}$ Department of Cardiology, National Heart Institute, Cairo, Egypt. ${ }^{3}$ Legacy employee, Research, Development and Medical, Pfizer Upjohn, Dubai, United Arab Emirates. ${ }^{4}$ Medical Affairs, Viatris, Cairo, Egypt.

Received: 5 March 2021 Accepted: 16 November 2021

Published online: 01 December 2021

\section{References}

1. Collaborators. G 2019 D and I. Global burden of 369 diseases and injuries in 204 countries and territories, 1990-2019: a systematic analysis for the Global Burden of Disease Study 2019. Lancet. 2020;396(10258):1204-22. https://doi. org/10.1016/S0140-6736(20)30925-910258.

2. WHO. Noncommunicable diseases 2019. Available from:https://www.who. int/news-room/fact-sheets/detail/noncommunicable-diseases. 
3. McAloon CJ, Boylan LM, Hamborg T, Stallard N, Osman F, Lim PB, et al. The changing face of cardiovascular disease 2000-2012: An analysis of the world health organisation global health estimates data. Int J Cardiol. 2016;224: 256-64. https://doi.org/10.1016/j.jicard.2016.09.026.

4. Bovet P, Paccaud F. Cardiovascular disease and the changing face of global public health: a focus on low and middle income countries. Public Health Rev. 2011;33(2):397-415. https://doi.org/10.1007/bf033916432.

5. Attia I. Country report Egypt-- Structure of health care in Egypt. 2014 Available from:https://www.escardio.org/static-file/Escardio/Subspecialty/EA CPR/egypt-country-report.pdf.

6. Reda A, Soliman M, El Kersh A, Abdou W, Mostafa M, Beshay M, et al. The pattern of risk-factor profile in Egyptian patients with acute coronary syndrome: Phase II of the Egyptian cross-sectional CardioRisk project. Cardiovasc J Afr. 2019;30(2):87-94. https://doi.org/10.5830/CVJA-2018-0742.

7. World Health Organization. World Health Organization - Noncommunicable diseases (NCD) country profiles, 2018. Available from:https://www.who.int/ nmh/countries/egy_en.pdf?ua=1.

8. El Faramawy A, Youssef G, El Aroussy W, El Remisy D, El Deeb H, Abdel Aal $A$, et al. Registry of the Egyptian specialized hypertension clinics: patient risk profiles and geographical differences. J Hum Hypertens. 2020;34(7):520-7. https://doi.org/10.1038/s41371-019-0265-07.

9. Forouzanfar MH, Afshin A, Alexander LT, Anderson HR, Bhutta ZA, Biryukov $\mathrm{S}$, et al. Global, regional, and national comparative risk assessment of 79 behavioural, environmental and occupational, and metabolic risks or clusters of risks, 1990-2015: a systematic analysis for the global burden of disease study 2015. Lancet. 2016;388(10053):1659-724. https://doi.org/10.101 6/50140-6736(16)31679-810053

10. Ibrahim MM, Appel L, Rizk HH, Helmy S, Mosley J, Ashour Z, et al. Cardiovascular risk factors in normotensive and hypertensive Egyptians. J Hypertens. 2001;19(11):1933-40. https://doi.org/10.1097/00004872-200111 000-0000211.

11. Giannattasio C, Maloberti A, Magni G, Cassano G, Capsoni NGS. Hypertensive emergencies and urgencies: blood pressure management and its relationship with short and medium term outcome. J Hypertens. 2019; 37(6):e168-6.

12. Gaziano TA, Bitton A, Anand S, Abrahams-Gessel S, Murphy A. Growing epidemic of coronary heart disease in low- and middle-income countries. Curr Probl Cardiol. 2010;35(2):72-115. https://doi.org/10.1016/j.cpcardiol.2 009.10.0022.

13. Nascimento BR, Brant LCC, Moraes DN, Ribeiro ALP. Global health and cardiovascular disease. Heart. 2014;100(22):1743-9. https://doi.org/10.1136/ heartjnl-2014-30602622.

14. WHO. Hypertension 2019. Available from:https:/www.who.int/news-room/fa ct-sheets/detail/hypertension.

15. WHO, The global health observatory, Prevalence of raised total cholesterol ( $\geq 190 \mathrm{mg} / \mathrm{dl}$ ) n.d. Available from: https://www.who.int/data/gho/indicatormetadata-registry/imr-details/2382. Accessed 30 July 2021.

16. Egypt national STEPwise survey for noncommunicable diseases risk factors report 2017 Available from:https://www.who.int/ncds/surveillance/steps/ Egypt_STEPS_Survey_2017_Fact_Sheet.pdf.

17. Tawfik MY, Fahim AE, Ismail MA. Barriers to the utilization of cardiovascular risk prediction tools as perceived by primary health care and family physicians. Egypt J Community Med. 2015;33(1):15-32. https://doi.org/10.21 608/ejcm.2015.7131.

18. Hasan D, Emeash A, Mustafa S, Abdelazim G, El-din A. Hypertension in Egypt: a systematic review. Curr Hypertens Rev. 2015;10(3):134-41. https:// doi.org/10.2174/15734021116661412171118073.

19. Mohsen I M. Strategic plans for diagnosis, treatment \& control of hypertension. Ann Clin Hypertens. 2018;2(1):067-78. https://doi.org/10.2932 8/journal.ach.10010131.

20. Youssef RM, Moubarak II. Patterns and determinants of treatment compliance among hypertensive patients. East Mediterr Heal J. 2002;8(4-5): 579-92.

21. El Etriby A, Bramlage P, El Nashar A, Brudi P. The DYSlipidemia international study (DYSIS)-Egypt: a report on the prevalence of lipid abnormalities in Egyptian patients on chronic statin treatment. Egypt Hear J. 2013;65(3):22332. https://doi.org/10.1016/j.ehj.2013.05.0033.

22. Sobhy M, El Etriby A, El Nashar A, Wajih S, Horack M, Brudi P, et al. Prevalence of lipid abnormalities and cholesterol target value attainment in Egyptian patients presenting with an acute coronary syndrome. Egypt Hear J. 2018;70(3):129-34. https://doi.org/10.1016/j.ehj.2018.05.0013.
23. Reda A, Abdel-Rehim AA, Etman A, Afifi OSA. Centralized pan-middle east survey on the under-treatment of hypercholesterolemia: Results from the CEPHEUS study in Egypt. Cardiol Ther. 2014;3(1-2):27-40. https://doi.org/1 0.1007/s40119-014-0031-X1-2.

24. Alshamiri M, Ghanaim MMA, Barter P, Chang KC, Li JJ, Matawaran BJ, et al. Expert opinion on the applicability of dyslipidemia guidelines in Asia and the middle east. Int J Gen Med. 2018;11:313-22. https://doi.org/10.2147/ IJGM.S160555.

25. Ikeda N, Sapienza D, Guerrero R, Aekplakorn W, Naghavi M, Mokdad AH, et al. Control of hypertension with medication: a comparative analysis of national surveys in 20 countries. Bull World Health Organ. 2014;92(1):1019C. https://doi.org/10.2471/blt.13.1219541.

26. Mohsen Ibrahim M, Ibrahim A, Shaheen K, Nour MA. Lipid profile in Egyptian patients with coronary artery disease. Egypt Hear J. 2013;65(2):7985. https://doi.org/10.1016/j.ehj.2012.08.0052.

27. Ibrahim MM. Problem of hypertension in Egypt. Egypt Hear J. 2013;65(3): 233-4. https://doi.org/10.1016/j.ehj.2013.03.0053.

28. Devi R, Kanitkar K, Narendhar R, Sehmi K, Subramaniam K. A narrative review of the patient journey through the lens of non-communicable diseases in low- and middle-income countries. Adv Ther. 2020;37(12):4808-30. https:// doi.org/10.1007/s12325-020-01519-3.

29. Birnie KA, Ouellette C, Do Amaral T, Stinson JN. Mapping the evidence and gaps of interventions for pediatric chronic pain to inform policy, research, and practice: a systematic review and quality assessment of systematic reviews. Can J Pain. 2020;4(1):129-48. https://doi.org/10.1080/24740527.202 0.17573841 .

30. Miake-Lye IM, Mak S, Lee J, Luger T, Taylor SL, Shanman R, et al. Massage for pain: an evidence map. J Altern Complement Med. 2019;25(5):475-502. https://doi.org/10.1089/acm.2018.02825.

31. Snilstveit B, Vojtkova M, Bhavsar A, Gaarder M. Evidence gap maps - a tool for promoting evidence-informed policy and prioritizing future research. World Bank Policy Res Work Pap. 2013:6725 Available from:http://hdl.handle. net/10986/16941.

32. Bharatan $T$, Devi $R$, Huang $P$ - $H$, Javed A, Jeffers $B$, Lansberg $P$, et al. A methodology for mapping the patient journey for noncommunicable diseases in low- and middle-income countries. J Healthc Leadersh. 2021;13: 35-46. https://doi.org/10.2147/JHL.S288966.

33. Williams B, Mancia G, Spiering W, Rosei EA, Azizi M, Burnier M, et al. 2018 Practice guidelines for the management of arterial hypertension of the European Society of Hypertension and the European Society of Cardiology: ESH/ESC task force for the management of arterial hypertension. J Hypertens. 2018;36(12):2284-309. https://doi.org/10.1097/HJH. 000000000000196112

34. WHO. The Global Health Observatory. Geneva: World Health Organization; 2021. Available from: https://www.who.int/data/gho/indicator-metadataregistry/imr-details/2382.

35. Obaya M, Yehia M, Hamed L, Fattah AA. Comparative study between elderly and younger patients with acute coronary syndrome. Egypt J Crit Care Med. 2015;3(2-3):69-75. https://doi.org/10.1016/j.ejccm.2015.12.0022-3.

36. World Health Organization. Global status report on noncommunicable diseases. Geneva: World Health Organization; 2014. Available from: https://a pps.who.int/iris/bitstream/handle/10665/148114/9789241564854_eng.pdf.

37. Ibrahim MM, Rizk H, Appel $\sqcup$, El Aroussy W, Helmy S, Sharaf Y, et al. Hypertension prevalence, awareness, treatment, and control in Egypt: results from the Egyptian National Hypertension Project (NHP). Hypertension. 1995: 26(6 I):886-90. https://doi.org/10.1161/01.HYP.26.6.8866 I.

38. Egypt health issues survey 2015. Available from:https://dhsprogram.com/ pubs/pdf/FR313/FR313.pdf.

39. Soliman SS, Guseman EH, Haile ZT, Ice GH. Prevalence and determinants of hypertension unawareness in Egyptian adults: a cross-sectional study of data from the 2015 Egyptian Health Issues Study. Lancet Glob Heal. 2020;8: S20. https://doi.org/10.1016/s2214-109x(20)30161-3.

40. Reda A, Etman A, Abdel-Rahim A, Farag N, Sanad O, Salamah S. Centralized pan-middle east survey on the under-treatment of hypercholesterolemia: results from the CEPHEUS II study in Egypt. Cardiol Ther. 2017;6(1):105-20. https://doi.org/10.1007/s40119-017-0089-31.

41. World Health Organization. Egypt STEPS Survey 2011-12 Fact Sheet. Geneva: World Health Organization; 2012. p. 1-2. Available from: https://www.who. int/ncds/surveillance/steps/2011-2012_Egypt_FactSheet.pdf.

42. Ellabany E, Abdel-Nasser MA. Community based survey study On Noncommunicable diseases and their Risk Factors, Egypt. World Health 
Organization; 2006. p. 1-79. Available from: http://www.who.int/chp/steps/ STEPS_Report_Egypt_2005-06.pdfE.

43. Sarki AM, Nduka CU, Stranges S, Kandala NB, Uthman OA. Prevalence of hypertension in low- and middle-income countries: a systematic review and meta-analysis. Med (United States). 2015;94(50):1-16. https://doi.org/10.1 097/MD.000000000000195950.

44. Fryar CD, Ostchega Y, Hales CM, Zhang G, Kruszon-Moran D. Hypertension prevalence and control among adults: United States, 2015-2016. NCHS Data Brief. 2017;289(289):1-8.

45. Burnier M, Egan BM. Adherence in Hypertension: a review of prevalence, risk factors, impact, and management. Circ Res. 2019;124(7):1124-40. https://doi. org/10.1161/CIRCRESAHA.118.3132207.

46. Hassanein M. Adherence to antihypertensive fixed-dose combination among Egyptian patients presenting with essential hypertension. Egypt Hear J. 2020;72(1):10. https://doi.org/10.1186/s43044-020-00044-61.

47. Chowdhury MZI, Rahman M, Akter T, Akhter T, Ahmed A, Shovon MA, et al. Hypertension prevalence and its trend in Bangladesh: evidence from a systematic review and meta-analysis. Clin Hypertens. 2020;26(1). https://doi. org/10.1186/s40885-020-00143-11

48. Zhou B, Danaei G, Stevens GA, Bixby H, Taddei C, Carrillo-Larco RM, et al. Long-term and recent trends in hypertension awareness, treatment, and control in 12 high-income countries: an analysis of 123 nationally representative surveys. Lancet. 2019;394(10199):639-51. https://doi.org/10.1 016/S0140-6736(19)31145-610199.

49. Spannella F, Giulietti F, Di Pentima C, Sarzani R. Prevalence and control of dyslipidemia in patients referred for high blood pressure: the disregarded "double-trouble" lipid profile in overweight/obese. Adv Ther. 2019;36(6): 1426-37. https://doi.org/10.1007/s12325-019-00941-66.

50. Reda A, Elserafy AS, Farag E, Mostafa T, Farag N, Elbahry A, et al. Egyptian Association of Vascular Biology and Atherosclerosis ( EAVA ) consensus on the usage of proprotein convertase subtilisin / kexin type 9 ( PCSK9 ) inhibitors. Egypt Hear J. 2020;72(1):23. https://doi.org/10.1186/s43044-02000058-0.1

51. Pharm TWC, Bspharm YKY, Lin S, Tai S, Pharm C. A systematic review and meta-analysis on the therapeutic equivalence of statins. J Clin Pharm Ther. 2010;35(2):139-51. https://doi.org/10.1111/j.1365-2710.2009. 01085.x.2.

52. Mittal BV, Singh AK. Hypertension in the developing world: challenges and opportunities. Am J Kidney Dis. 2010;55(3):590-8. https://doi.org/10.1053/j.a jkd.2009.06.0443.

53. Today E. Health min.: "100 Million Healthy Lives" campaign "turning point" in Egypt's healthcare system. Egypt: Egypt Today; 2020. Available from: https://www.sis.gov.eg/Story/150325/Health-min.

54. Anand S, Bradshaw C, Prabhakaran D. Prevention and management of CVD in LMICs: Why do ethnicity, culture, and context matter. BMC Med. 2020; 18(1):1-5. https://doi.org/10.1186/s12916-019-1480-91.

55. Lin CF, Chang YH, Chien SC, Lin YH, Yeh HY. Epidemiology of dyslipidemia in the Asia Pacific region. Int J Gerontol. 2018;12(1):2-6. https://doi.org/10.1 016/j.ijge.2018.02.0101.

56. (UNICEF) WHO\& UNICEF. A vision for primary health care in the 21st century: towards universal health coverage and the sustainable development goals. Geneva: World Health Organization; 2018. Available from: https://apps.who.int/iris/handle/10665/328065.

57. Pati MK, Swaroop N, Kar A, Aggarwal P, Jayanna K, Van Damme W. A narrative review of gaps in the provision of integrated care for noncommunicable diseases in India. Public Health Rev. 2020;41(1):1-16. https://doi.org/10.1186/s40985-020-00128-31.

58. Joshi R, Jan S, Wu Y, MacMahon S. Global inequalities in access to cardiovascular health care. Our greatest challenge. J Am Coll Cardiol. 2008; 52(23):1817-25. https://doi.org/10.1016/j.jacc.2008.08.04923.

59. Liu X, Yu S, Mao Z, Li Y, Zhang H, Yang K, et al. Dyslipidemia prevalence, awareness, treatment, control, and risk factors in Chinese rural population: the Henan rural cohort study. Lipids Health Dis. 2018;17(1):1-12. https://doi. org/10.1186/s12944-018-0768-71.

60. Reiger S, Jardim TV, Abrahams-Gessel S, Crowther NJ, Wade A, Gomez-Olive FX, et al. Awareness, treatment, and control of dyslipidemia in rural South Africa: The HAALSI (Health and Aging in Africa: a longitudinal study of an INDEPTH community in South Africa) study. PLoS ONE. 2017;12(10):1-12. https://doi.org/10.1371/journal.pone.018734710.

61. Abolfotouh MA, Soliman LA, Abolfotouh SM, Raafat M. Knowledge and practice of PHC physicians toward the detection and management of hypertension and other CVD risk factors in Egypt. Int J Hypertens. 2011; 2011:983869-6. https://doi.org/10.4061/2011/983869

62. WHO Country Cooperation Strategy. Geneva: World Health Organization; 2016. Available from: https://apps.who.int/iris/bitstream/handle/10665/251 734/WHO-CCU-16.04-eng.pdf.

63. Berman P, Nandakumar AK, Frere J-J, Salah H, El-Adawy M, Saharty SE-, et al. A reform strategy for primary care in Egypt. Technical Report 9. Bethesda, MD: Partnerships for health reform project, Abt Associates Inc. 1997. Available from: https://cdn1.sph.harvard.edu/wp-content/uploads/sites/1 989/2020/01/Egypt_-A-Reform-Strategy-for-Primary-Care-in-Egypt.pdf.

64. Piepoli MF, Hoes AW, Agewall S, Albus C, Brotons C, Catapano AL, et al. 2016 European guidelines on cardiovascular disease prevention in clinical practice. Eur Heart J. 2016;37(29):2315-81. https://doi.org/10.1093/eurheartj/ ehw10629.

65. International Diabetes Federation (IDF). Follow-up to the political declaration of the high-level meeting of the general assembly on the prevention and control of non-communicable diseases. Sixty Sixth World Heal Assem. Geneva: World Health Organization; 2013. Available from: https://apps.who.int/gb/ebwha/pdf_files/WHA66/A66_R10-en.pdf.

66. Bayoumi S. Health and social justice in Egypt : towards a health equity perspective. World Soc Sci Rep. 2016:140-3 Available from: https://en. unesco.org/inclusivepolicylab/sites/default/files/analytics/document/2019/4/ wssr_2016_chap_30.pdf.

67. Rafeh. N, Julie W, Nagwan H. Egypt household health expenditure and utilization survey 2010. 2011. Available from: https://www.hfgproject.org/ egypt-household-health-expenditure-utilization-survey-2010/

68. The world bank. Egypt: World bank provides US $\$ 400$ million in support of universal health insurance system. 2020. Available from: https://www. worldbank.org/en/news/press-release/2020/06/16/egypt-world-bankprovides-us-400-million-in-support-of-universal-health-insurance-system.

69. Fouda S, Kelany M, Moustafa N, Abushouk Al, Hassane A, Sleem A, et al. Tobacco smoking in Egypt: a scoping literature review of its epidemiology and control measures. East Mediterr Heal J. 2018;24(2):198-215. https://doi. org/10.26719/2018.24.2.1982

70. Frieden TR, Berwick DM. The "Million Hearts" initiative — preventing heart attacks and strokes. N Engl J Med. 2011;365(13):e27. https://doi.org/10.1056/ NEJMp111042113.

71. Vrijens B, Antoniou S, Burnier M, de la Sierra A, Volpe M. Current situation of medication adherence in hypertension. Front Pharmacol. 2017;8(MAR):1-8. https://doi.org/10.3389/fphar.2017.00100MAR.

72. Farid SF. Conceptual framework of the impact of health technology on healthcare system. Front Pharmacol. 2019;10(7):1-10. https://doi.org/10.33 89/fphar.2019.009337.

73. International Finance. Egypt is accelerating digitisation in healthcare. 2020. Available from: https://internationalfinance.com/egypt-is-accelerating-digitisa tion-in-healthcare/. Accessed 30 Jan 2021.

\section{Publisher's Note}

Springer Nature remains neutral with regard to jurisdictional claims in published maps and institutional affiliations.

\section{Submit your manuscript to a SpringerOpen ${ }^{\circ}$ journal and benefit from:}

- Convenient online submission

- Rigorous peer review

- Open access: articles freely available online

- High visibility within the field

- Retaining the copyright to your article

Submit your next manuscript at $\boldsymbol{\nabla}$ springeropen.com 